\title{
mGluR5 Antagonist MPEP Reduces Ethanol-Seeking and Relapse Behavior
}

\author{
Pia Bäckström 1,3, Daniel Bachteler*,2,3, Sabrina Koch², Petri Hyytiä' and Rainer Spanagel ${ }^{2}$ \\ 'National Public Health Institute, Helsinki, Finland; '² Department of Psychopharmacology, University of Heidelberg, Central Institute of Mental \\ Health (CIMH), Mannheim, Germany
}

\begin{abstract}
The glutamatergic system plays an important role in mediating neurobehavioral effects of ethanol. Metabotropic glutamate receptors subtype 5 (mGluR5) are modulators of glutamatergic neurotransmission and are abundant in brain regions known to be involved in ethanol self-administration. Here, we studied the effects of 2-methyl-6-(phenylethynyl)-pyridine (MPEP), a highly potent, noncompetitive mGlu5 receptor antagonist, on voluntary ethanol consumption and relapse behavior. For this purpose, we used two models for the measurement of relapse behavior: (i) reinstatement of ethanol-seeking behavior by drug-associated cues and (ii) the alcohol deprivation effect in long-term ethanol-consuming rats. In the first set of experiments, rats were trained to lever press for ethanol in the presence of a distinct set of cues. After extinction, the animals were exposed to the respective cues that initiated reinstatement of responding. A response-contingent ethanol prime further enhanced responding compared to the conditioned cues alone. Under these conditions, $\operatorname{MPEP}(0,1,3$, and $10 \mathrm{mg} / \mathrm{kg})$ attenuated ethanol seeking significantly and in a dose-related manner. However, at the highest dose, MPEP also decreased the number of inactive lever responses. In the second set of experiments, rats with I year of ethanol experience and repeated deprivation phases were used. A subchronic treatment with MPEP (twice daily; 0,3 , and $10 \mathrm{mg} / \mathrm{kg}$ ) resulted in a significant and dose-dependent reduction of the alcohol deprivation effect (ADE). Although the same MPEP treatment regimen decreased baseline drinking, this effect was not as pronounced as on the ADE. These results show in two commonly used models of relapse to ethanol that pharmacological targeting of mGlu5 receptors may be a promising approach for the treatment of alcoholism.

Neuropsychopharmacology (2004) 29, 92 I-928, advance online publication, 2 I January 2004; doi: I 0. I 038/sj.npp. I 30038 I
\end{abstract}

Keywords: mGluR5; MPEP; reinstatement; discriminative stimulus; ethanol priming; alcohol deprivation effect

\section{INTRODUCTION}

The neurobiological and molecular basis of relapse to ethanol is still not well understood; however, preclinical as well as clinical data imply that relapse can be induced through different pathways (Spanagel and Zieglgänsberger, 1997; Lê and Shaham, 2002; Weiss and Porrino, 2002). One pathway seems to involve the glutamatergic system (Tsai and Coyle, 1998), where chronic alcohol intake leads to compensatory changes. During withdrawal and abstinence, increased glutamatergic excitatory neurotransmission leads to a state of hyperexcitability, which may then be associated with an enhanced risk to relapse (Tsai and Coyle, 1998; Spanagel and Bienkowski, 2002). Diminishing the activity of

\footnotetext{
*Correspondence: D Bachteler, Department of Psychopharmacology, University of Heidelberg, Central Institute of Mental Health (CIMH), J5, Mannheim 68159, Germany, Tel: + 49-621-1703835, Fax: + 49-6211703837, E-mail: dbach@zi-mannheim.de

${ }^{3}$ Both these authors contributed equally to this work

Received 22 July 2003; revised 17 November 2003; accepted 09 December 2003

Online publication: 16 December 2003 at http://www.acnp.org/ citations/Npp I 2 1 60303322/default.pdf
}

a hyperexcited glutamatergic system might be a promising therapeutic approach in order to reduce the risk to relapse in abstinent patients. From a pharmacological point of view, this can be best achieved by targeting postsynaptic glutamate receptors. A variety of postsynaptic glutamate receptors exist; however, the metabotropic glutamate receptor subtype 5 (mGluR5) has recently received considerable attention due to its abundance in brain regions known to be involved in drug reinforcement (Shigemoto et al, 1993; Romano et al, 1995; Lu et al, 1999; Wang et al, 2003). In addition, the initial report by Chiamulera et al (2001) demonstrated the absence of cocaine self-administration in mGluR5 knockout mice and the dose-dependent reduction of cocaine self-administration following the administration of the selective antagonist 2-methyl-6(phenylethynyl)-pyridine (MPEP) (Gasparini et al, 1999). Taking these findings into consideration, we hypothesized that mGluR5 might be a promising pharmacological target for the prevention of relapse to alcohol.

To test this hypothesis, we studied the effects of MPEP in two commonly used models of relapse; namely, the reinstatement model and the alcohol deprivation model (see, for review, Spanagel, 2000; Lê and Shaham, 2002; 
Shaham et al, 2003). In the reinstatement paradigm, the animal is trained under operant conditions to self-administer ethanol and is then subjected to extinction. Following extinction, various conditions have been reported to lead to reinstatement of ethanol seeking, including ethanol priming and stress (Lê et al, 1998). However, the most reliable reinstatement of ethanol seeking has been obtained after presenting the subjects with stimuli previously associated with ethanol availability (Katner et al, 1999; Ciccocioppo et al, 2001; Liu and Weiss, 2002).

Another animal model to study relapse-like behavior is the alcohol deprivation effect (ADE) (see, for review, Spanagel and Hölter, 1999). In this model, alcoholexperienced animals show a transient increase in alcohol consumption and alcohol preference after a period of forced abstinence (alcohol deprivation). This robust effect can be observed under home cage drinking and under operant conditions in various species, including monkeys (Sinclair, 1971).

Both models have now been pharmacologically validated with antirelapse compounds that are clinically used for treating alcoholics (Spanagel and Hölter, 2000; Lê and Shaham, 2002). In conclusion, there appears to be a good correspondence between the events that induce relapse in rats and those that provoke relapse in humans.

\section{MATERIALS AND METHODS}

\section{Animals}

Tests for reinstatement were carried out using 10 male Long-Evans rats (HsdBlu:LE, Harlan Sprague-Dawley, Indianapolis, IN) weighing $200-250 \mathrm{~g}$ at the start of experiments. The animals were housed in pairs in Macrolon IV cages in a temperature- and humidity-controlled room under a 12-h light/dark cycle (lights on at noon). Water and pellet food (RM1, SDS, Witham, UK) were available ad libitum in the home cage except during initial training (see below). All behavioral testing was carried out during the dark phase of the light/dark cycle between 0800 and 1100, 5 days a week.

For the experiments on the ADE and baseline drinking, 30 male Wistar rats (Martinsried, Germany), weighing 260$300 \mathrm{~g}$ at the start of the experiment, were housed individually in standard hanging rodent cages (Ehret, Emmendingen, Germany) on a 12-h light/dark cycle with lights on at 0700. Animals were provided with food (Ssniff, Soest, Germany), tap water, and 5, 10, and 20\% (v/v) ethanol solutions ad libitum for 12 months.

All experimental procedures were approved by the respective Committees on Animal Care and Use, and carried out following the local Animal Welfare Acts and in accordance with the European Communities Council Directive of 24 November 1986 (86/609/EEC).

\section{Drugs}

MPEP (Alexis Biochemicals, Lausen, Switzerland) was used in all experiments as its hydrochloride salt dissolved in saline $(0.9 \%)$. To obtain complete effects of MPEP in the home cage experiments (ADE and baseline drinking), rats received two intraperitoneal (i.p.) injections per day. MPEP was administered for a total of 3 days twice daily at 0800 and 1800 .

\section{Reinstatement Procedure}

Ethanol self-administration. All training and testing procedures took place in operant chambers (Lafayette Instrument, Lafayette, IN) enclosed in ventilated soundattenuating cubicles. The chambers were equipped with two response levers on each side of the two drinking cups in the center of the front panel. A stimulus light was mounted above the right response lever. Auditory stimuli $(2.9 \mathrm{kHz}$, $65 \mathrm{~dB}$ ) were delivered from a loudspeaker positioned on top of the self-administration chamber. Responses at the appropriate lever activated a syringe pump that delivered a $0.1 \mathrm{ml}$ drop of fluid into one of the two drinking cups. Rats were trained to self-administer ethanol orally in daily 30min sessions using a saccharin fading procedure. Briefly, rats were placed on a 12-h water deprivation for 3 consecutive days and were trained to respond for a $0.1 \mathrm{ml}$ drop of $0.2 \%(\mathrm{w} / \mathrm{v})$ saccharin solution on both levers under a fixed ratio 1 (FR1) schedule of reinforcement. After this initial training, water deprivation was terminated and animals had free access to food and water throughout the subsequent training and testing. During the next three sessions, responses at the right lever resulted in the delivery of $0.1 \mathrm{ml}$ of $5 \%(\mathrm{w} / \mathrm{v})$ ethanol $+0.2 \%$ saccharin solution. Responses at the left lever were recorded but had no programmed consequences. Thereafter, the concentration of ethanol was increased first to $8 \%$ and then to $10 \%(\mathrm{w} / \mathrm{v})$, while the concentration of saccharin was decreased until saccharin was eliminated completely from the drinking solution over a period of 13 sessions.

Conditioning and extinction procedures. During conditioning, discriminative stimuli were established that predicted availability of $10 \%$ ethanol and an alternate fluid with low reinforcing properties. Preliminary tests showed that rats also responded for water at relatively high rates. Therefore, $80 \mu \mathrm{M}$ quinine solution was offered as the nonreinforcing fluid. Beginning with self-administration training with the $10 \%$ ethanol concentration, olfactory discriminative stimuli $\left(\mathrm{S}^{\mathrm{D}}\right)$ predicting either ethanol or $80 \mu \mathrm{M}$ quinine hydrochloride solution availability were presented during self-administration sessions. Ethanol availability was signaled by anise odor $\left(\mathrm{S}^{+}\right)$, whereas quinine availability (ie nonreward) was signaled by grapefruit odor $\left(\mathrm{S}^{-}\right)$. The olfactory stimuli were generated by placing a small piece of absorbent paper containing a drop of either anise or grapefruit essential oil next to the selfadministration chamber inside the sound-attenuation cubicle immediately before the session. In addition to these discriminative stimuli, each lever press resulting in ethanol delivery was accompanied by a 3-s light stimulus $\left(\mathrm{CS}^{+}\right)$, whereas a 3-s auditory stimulus $\left(\mathrm{CS}^{-}\right)$was presented with quinine delivery. During the first week of the 7-week conditioning phase, rats were given ethanol sessions only. Thereafter, ethanol and quinine sessions were given in a random order until rats received a total of 18 ethanol and 18 quinine sessions. Subjects were then subjected to $30-\mathrm{min}$ extinction sessions, during which responding had no programmed consequences and the olfactory stimuli 
signaling ethanol or quinine availability were withheld. Extinction sessions continued for a total of 20 sessions.

Reinstatement tests. Reinstatement sessions began on day 1 postextinction. During the first session, rats were presented with $S^{\mathrm{D}}$ predictive of quinine availability (grapefruit odor), and responses on the previously active lever resulted in the 5 -s presentation of the auditory stimulus and activation of the syringe pump motor, but not in the delivery of drinking solution. During the next sessions, rats were tested for ethanol-seeking behavior under two reinstatement conditions: with $\mathrm{S}^{+} / \mathrm{CS}^{+}$present and with $\mathrm{S}^{+} / \mathrm{CS}^{+}$accompanied by response-contingent $0.2 \mathrm{ml}$ oral ethanol priming. Both sessions were initiated by the presentation of the ethanolassociated $S^{\mathrm{D}}$ (anis odor), and active lever responses were followed by the activation of syringe motor and presentation of ethanol-associated $\mathrm{CS}^{+}$, the 5-s light. In addition, during the session with ethanol priming, the first two lever responses produced a $0.1 \mathrm{ml}$ ethanol solution to the drinking cup. Half of the subjects were tested under the $\mathrm{S}^{+} / \mathrm{CS}^{+}$condition on day 2 postextinction and the $\mathrm{S}^{+} /$ $\mathrm{CS}^{+}$/ethanol priming condition on day 4 postextinction. On intervening days, rats remained in their home cages. The conditions were reversed for the other half of the animals.

Effect of MPEP on reinstatement. The effect of MPEP on ethanol-seeking behavior was examined using the reinstatement procedure with the ethanol priming described above $\left(\mathrm{S}^{+} / \mathrm{CS}^{+} /\right.$ethanol priming). Reinstatement testing was conducted twice a week with the rats confined to their home cages on intervening days. MPEP was administered $30 \mathrm{~min}$ prior to the sessions in a Latin-square, withinsubjects design $(0,1,3$, and $10 \mathrm{mg} / \mathrm{kg})$.

\section{ADE Procedure and Baseline Drinking}

Long-term ethanol self-administration. After 1 week of habituation to the animal room, all rats were given continuous access to tap water and to 5,10 , and $20 \%(\mathrm{v} / \mathrm{v})$ ethanol solutions in their home cages. Spillage and evaporation were minimized by the use of bottle caps with ball bearings (Ehret, Emmendingen, Germany). With this procedure, the ethanol concentration in a given solution stayed constant for at least 1 week (see Hölter et al, 1998). All drinking solutions were renewed weekly and at that time, the positions of the four bottles were changed to avoid location preferences. After the initial 8 weeks of continuous ethanol access, every 4 weeks of drinking were followed by a deprivation phase of two weeks. At the end of the eighth deprivation phase the animals were used for the experiments.

$A D E$ measurement. Baseline measures were determined by daily weighing of the bottles and the animals at 1000 for three preabstinence days. Daily ethanol intake, weight changes, total fluid intake, total ethanol preference, and preferences for the three ethanol solutions were calculated from these measurements. After the last day of measurement, the ethanol bottles were removed from the cages leaving the animals with food and tap water ad libitum. After 14 days, the ethanol solutions were presented again to the animals at 1000 and the daily weighing routine was reintroduced for 4 postabstinence days to assess the ADE.

Effects of MPEP on baseline drinking and the ADE. The effects of subchronic MPEP treatment on baseline drinking and the ADE were determined in rats with 12 months of ethanol experience in the long-term paradigm described above.

For evaluating the effects of MPEP on baseline drinking, the animals were divided into three groups $(n=10$ each) and treated with two doses of MPEP ( 3 and $10 \mathrm{mg} / \mathrm{kg}$, i.p.) and saline for 3 subsequent days. After 4 weeks, the animal groups were subjected to a deprivation phase for 14 days to assess the effects of MPEP on the ADE. The first two injections of MPEP were given prior to the representation of the ethanol bottles. To ensure that previous MPEP treatment during baseline drinking did not influence our ADE measurements animal groups received different treatment during $\mathrm{ADE}$ and baseline drinking.

\section{Locomotor Activity}

Locomotor activity testing was carried out in 24 Wistar rats that underwent the long-term ethanol self-administration procedure with repeated deprivation phases. The animals were put into a sound-attenuated experimental room $12 \mathrm{~h}$ before testing. Animals were divided into three groups ( $n=8$ per group). According to a detailed time schedule, the treatment groups received either two injections of MPEP $(10 \mathrm{mg} / \mathrm{kg} ; 12 \mathrm{~h}$ and $1 \mathrm{~h}$ prior to the activity measurement $)+$ ethanol $(0.5 \mathrm{~g} / \mathrm{kg}, 12 \% \mathrm{v} / \mathrm{v}$ i.p. in saline $)$ or two injections of saline + ethanol, respectively. Control animals accordingly received three injections of saline. Measurements started immediately after the injection of ethanol. Activity monitoring was conducted in square-shaped boxes $(49 \times 49 \times 38 \mathrm{~cm}(L \times W \times H))$ and illuminated from above with 25 Lux. Rats were placed individually into the boxes and activity was monitored in 20-min bins for $2 \mathrm{~h}$ by a video camera (Sony CCD-IRIS). The recorded data were analyzed using the image processing system EthoVision 3.0 (Noldus Information Technology, Wageningen, The Netherlands).

Data analysis. In the reinstatement experiments, the number of active and inactive lever responses across the reinstatement conditions and MPEP doses was analysed using one-way ANOVA with repeated measures. In experiments using the alcohol deprivation model, treatment effects on postabstinence days were assessed by two-way ANOVA with repeated measures (treatment $x$ days). Locomotor activity experiments were analyzed using one-way ANOVA. The accepted level of significance was $p \leqslant 0.05$. Newman-Keuls test was applied for post hoc comparisons when appropriate.

\section{RESULTS}

\section{MPEP Dose-Dependently Reduced Cue-Induced Reinstatement of Ethanol-Seeking Behavior}

Following the saccharin fading procedure, rats developed stable responding for $10 \%$ ethanol during the 18 conditioning sessions. The mean $( \pm$ SEM) number of responses for 
ethanol during the final three sessions was $32.0 \pm 3.6$, corresponding to an ethanol intake of $0.53 \pm 0.05 \mathrm{~g} / \mathrm{kg}$, while the number of inactive lever responses was $6.4 \pm 1.7$. At the same time, the number of quinine responses decreased, reaching the level of $11.9 \pm 2.0$ responses during the last three sessions. The number of inactive lever responses during these sessions was $9.9 \pm 2.2$.

Figure 1a shows that exposure of subjects to the $\mathrm{S}^{+} / \mathrm{CS}^{+}$ stimulus conditions reliably reinstated responding on the previously active lever above the extinction level, while the quinine-associated $\mathrm{S}^{-} / \mathrm{CS}^{-}$condition failed to alter responding (factor condition $\mathrm{F}(3,27)=29.74, p<0.0001$ ). Further analyses indicated that the response-contingent $0.2 \mathrm{ml}$ ethanol prime significantly enhanced responding compared to the $\mathrm{S}^{+} / \mathrm{CS}^{+}$alone $(\mathrm{F}(1,9)=15.11, p=0.004)$.

a

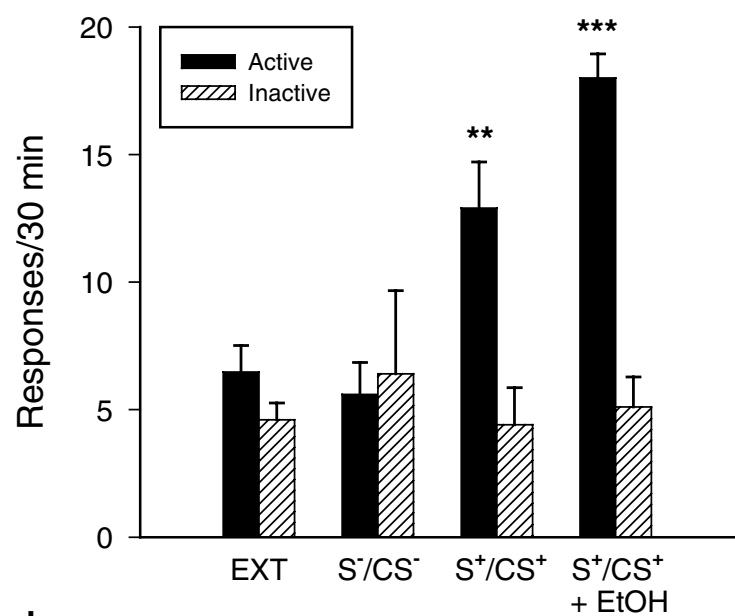

b

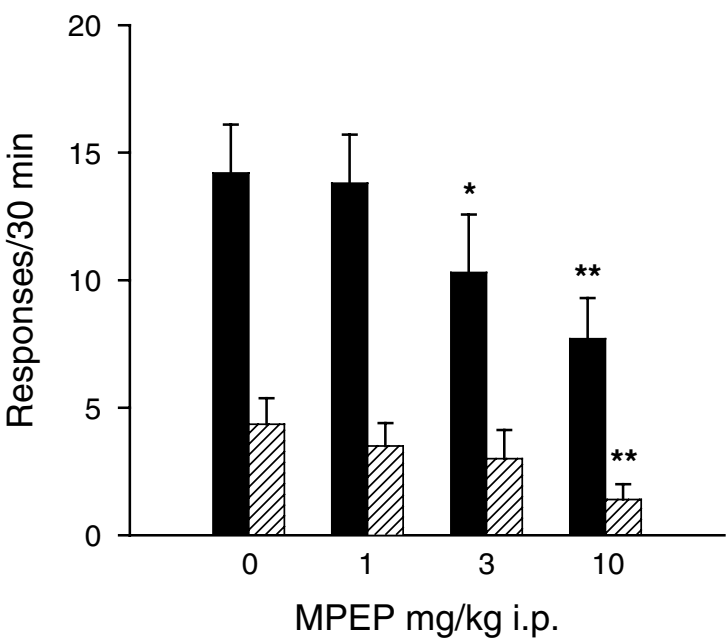

Figure I Reinstatement of ethanol responding under stimulus conditions associated with ethanol and quinine availability (a) and modulation of ethanol responding with $\operatorname{MPEP}(0, \mathrm{I}, 3$, and $10 \mathrm{mg} / \mathrm{kg}$; i.p.) (b). EXT, responses during the final three extinction sessions; $\mathrm{S}^{-} / \mathrm{CS}^{-}$, responses during stimuli predictive of quinine availability; $\mathrm{S}^{+} / \mathrm{CS}^{+}$and $\mathrm{S}^{+} / \mathrm{CS}^{+} /$ $\mathrm{EtOH}$, responses during stimuli predictive of ethanol availability. The effects of MPEP were tested under the $\mathrm{S}^{+} / \mathrm{CS}^{+} / \mathrm{EtOH}$ condition following the first reinstatement sessions. Shown are the mean $( \pm S E M)$ numbers of responses at the previously active and inactive levers during 30-min sessions in 10 rats. $* p<0.05$, $* * * 0.01$, $* * * * 0<0.00$ I, significantly different from the baseline or vehicle condition, paired t-tests.
Since this ethanol volume corresponded to an ethanol intake of only $0.04 \mathrm{~g} / \mathrm{kg}$ in these rats, it is likely that orosensory rather than central effects of ethanol were responsible for enhanced responding.

The mGluR5 antagonist MPEP attenuated ethanol seeking significantly and in a dose-related manner in the $\mathrm{S}^{+} / \mathrm{CS}^{+}$/ ethanol condition $(\mathrm{F}(3,27)=8.56, p<0.0001)$. However, at the highest $10 \mathrm{mg} / \mathrm{kg}$ dose, MPEP also decreased the number of the inactive lever responses $(\mathrm{F}(3,27)=3.55, p=0.028)$ (Figure 1b).

\section{MPEP Dose-Dependently Reduced the ADE}

At first, the effect of subchronic MPEP treatment on basal alcohol intake was measured (Figure 2a). Animals consumed on an average $2.9 \pm 0.15 \mathrm{~g} / \mathrm{kg}$ ethanol per day.
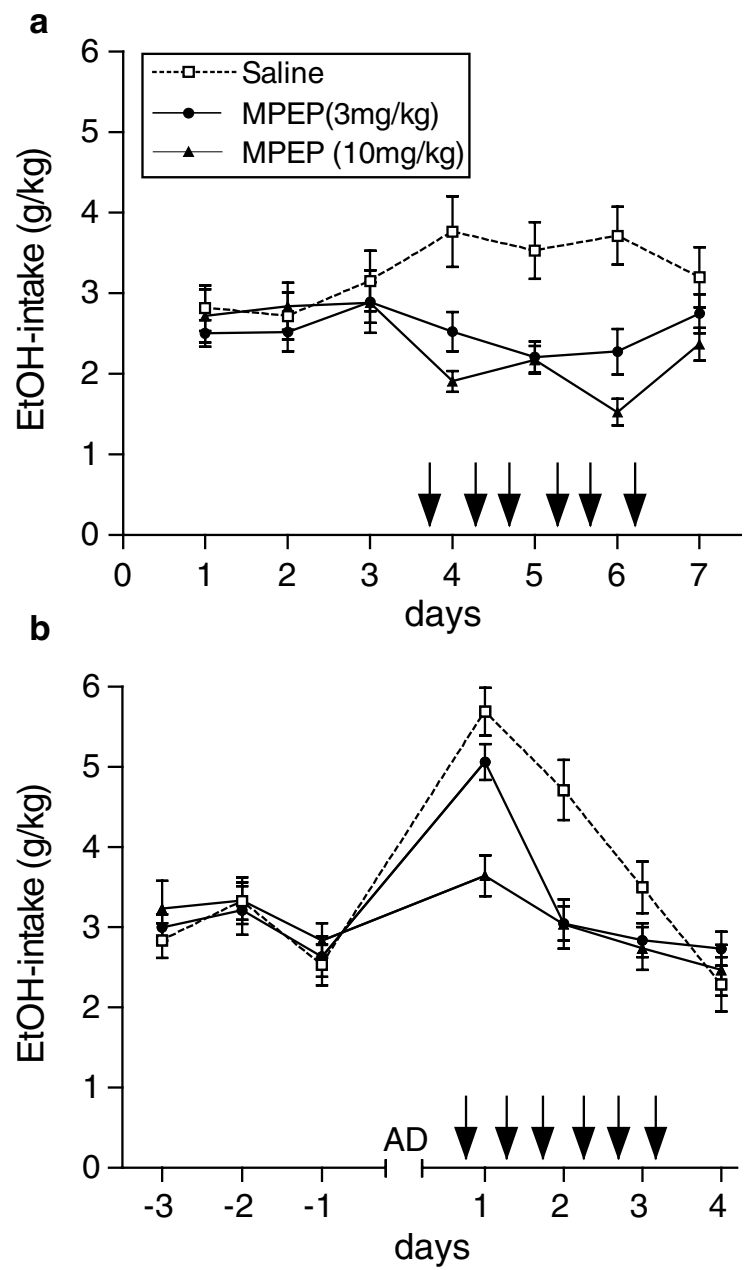

Figure 2 Effects of $\operatorname{MPEP}(0,3$, and $10 \mathrm{mg} / \mathrm{kg}$; i.p.) on ethanol intake in rats that consumed voluntarily ethanol for I year and underwent repeated deprivation phases. In (a) the effects of subchronic MPEP treatment on baseline drinking is shown and in (b) its effects on the ADE are illustrated. The figures show the mean daily alcohol intake in $g$ ethanol $/ \mathrm{kg}$ bodyweight $( \pm S E M)$ obtained in 10 rats per group. Arrows indicate MPEP injections Measurements were taken during the last 3 days before deprivation $(A D=$ alcohol deprivation $)$ and first 4 days after representation of ethanol. Significant differences were found for both treatment groups: on days 4-6 (baseline drinking, a) and for the first 3 postdeprivation days (ADE, b) compared to the saline control group. For reasons of clarity of the figures asterisks are not shown here. 
Subchronic treatment of MPEP over 3 days produced a significant attenuation of basal ethanol intake in both treatment groups compared to the control group (treatment: $\mathrm{F}(2,27)=5.337, p=0.011)$. However, this effect was mainly due to an increase in the saline control group over days (factor time: $\mathrm{F}(6,54)=3.372, p=0.007$ ). It is suggested that multiple saline injections were stressful to the animals and that they slightly increased their ethanol intake over days - a phenomenon that we have already observed previously (Spanagel and Hölter, 1999). In contrast, MPEP injections had no significant effect over the time course of the experiment (factor time: $\mathrm{F}(6,162)=1.438, p=0.203$ ).

After 2 weeks of abstinence, a significant ADE occurred characterized by a transient increase in ethanol intake (factor ADE: $\mathrm{F}(6,54)=30.782, p<0.001$ ) during the 4 postabstinence days in comparison with the 3 preabstinence days (Figure $2 b$ ). Figure $2 b$ shows further the influence of $\operatorname{MPEP}(0,3$, and $10 \mathrm{mg} / \mathrm{kg}$; i.p.) given twice daily for 3 days on the ADE. In comparison to the effect of saline in control animals, MPEP dose-dependently diminished alcohol intake on representation after the deprivation period. Two-way analysis of variance with repeated measures over 4 days after withdrawal revealed a significant effect of treatment $[\mathrm{F}(2,27)=5.143, \quad p=0.013]$, a significant effect of days $[\mathrm{F}(3,81)=92.983, p<0.001]$, and a significant interaction between factors $[\mathrm{F}(6,81)=11.467, p<0.001]$. Post hoc analysis (Newman-Keuls test) showed a significant difference between the treatment groups and controls on the 3 postdeprivation days.

Subchronic MPEP treatment had no influence on body weight and water intake: body weight: before treatment $547 \pm 10 \mathrm{~g}$, after treatment $548 \pm 9 \mathrm{~g}$ in the saline group and before treatment $549 \pm 6 \mathrm{~g}$, after treatment $545 \pm 5 \mathrm{~g}$ in the MPEP group $(10 \mathrm{mg} / \mathrm{kg})$. Water intake before treatment $8.0 \pm 1 \mathrm{~g} / \mathrm{kg}$, after treatment $8.6 \pm 1 \mathrm{~g} / \mathrm{kg}$ in the saline group and before treatment $7.3 \pm 0.9 \mathrm{~g} / \mathrm{kg}$, after treatment $6.7 \pm 0.9 \mathrm{~g} / \mathrm{kg}$ in the MPEP group $(10 \mathrm{mg} / \mathrm{kg})$.

\section{MPEP Treatment did not Produce Sedative Effects}

Ethanol at the applied low dose $(0.5 \mathrm{~g} / \mathrm{kg})$ increased locomotor activity for $2 \mathrm{~h}$; however, MPEP treatment $(10 \mathrm{mg} / \mathrm{kg})$ decreased the resulting activity to the level of the saline-treated control animals (Figure 3). One-way ANOVA revealed no significant treatment effects following ethanol + MPEP treatment $(\mathrm{F}(2,21)=0.886 ; p=0.43)$.

\section{DISCUSSION}

The effects of the selective mGluR5 antagonist MPEP were tested in two commonly used models of relapse to ethanol drinking. In both models, MPEP significantly reduced relapse-like behavior in a dose-dependent manner. MPEP also affected baseline drinking under home cage conditions; however, this effect was not as pronounced as on relapselike drinking behavior.

MPEP was first tested in a rat model of cue-induced reinstatement of ethanol-seeking behavior. For this purpose, distinct cues (smell and light) were paired with ethanol responding. Following extinction this set of distinct cues renewed responding on the ethanol lever, an effect that

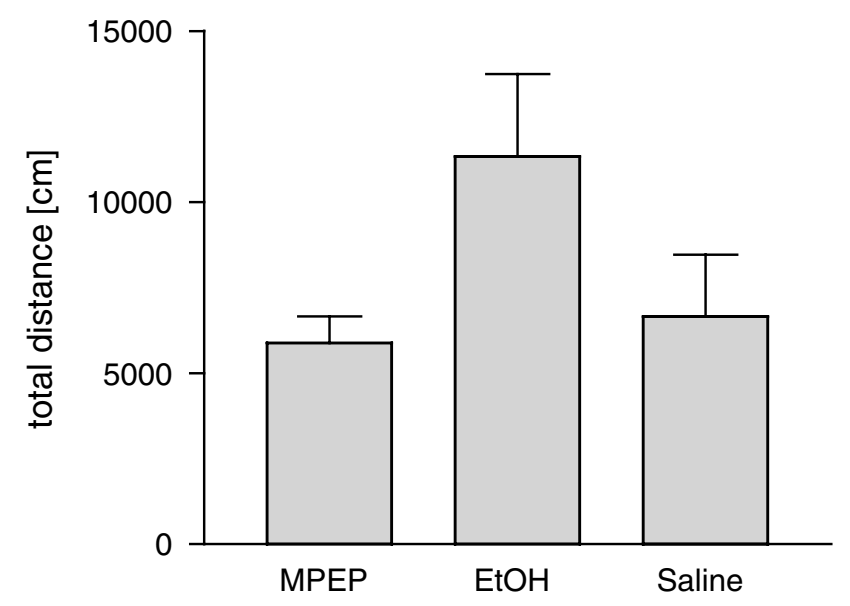

Figure 3 Effects of MPEP and ethanol injections on locomotor activity compared to saline controls in eight rats/group. Treatment groups received two injections of MPEP $+\mathrm{EtOH}$ or two injections of saline $+\mathrm{EtOH}$, respectively. Controls were treated with saline. The bars show the total distance $( \pm$ SEM) moved during $2 \mathrm{~h}$.

was further augmented by contingent ethanol priming. With ethanol priming, the rats were presented with two additional ethanol-associated cues, the odor and taste of ethanol that were present during conditioning and were not subjected to extinction because quinine conditioning sessions and extinction training were conducted with no ethanol in the fluid delivery system. It is therefore possible that enhanced responding seen after ethanol priming was caused by simultaneous presentation of all constituents of the stimulus complex present during conditioning. However, it has been found previously that presentation of a liquid dipper containing either ethanol or water reinstated responding, suggesting that nonspecific sensory properties of the liquid made available may also contribute to reinstatement (Bienkowski et al, 2000). This possibility was not investigated in our study. Furthermore, we do not know whether the small oral priming dose of ethanol alone could have reinstated responding, or whether the environmental cues associated with ethanol availability and the orosensory properties of ethanol acted additively to induce reinstatement. In this context, it is worth noting that although contingent or injected ethanol have been previously reported to reinstate ethanol responding, this effect shows high variability and inconsistency (Chiamulera et al, 1995; Lê et al, 1998, 1999; Vosler et al, 2001; Lê and Shaham, 2002).

Under the described conditions, MPEP significantly reduced reinstatement of ethanol-seeking behavior. As the priming dose of ethanol was very small (on average $0.04 \mathrm{~g} /$ $\mathrm{kg}$ ), it is likely that MPEP reduced the ability of the stimulus complex associated with ethanol (ie the environmental cues and orosensory properties of ethanol) to reinstate lever pressing rather than counteracted the central pharmacological effects of ethanol. Similarly, MPEP has been shown to attenuate the expression of other conditioned behaviors, including conditioned fear, morphine- and cocaine-induced place preference, and taste aversion (Schulz et al, 2001; Popik and Wrobel, 2002; McGeehan and Olive, 2003; Schachtman et al, 2003). 
With the MPEP doses used, no nonspecific effects on behavior were observed, but at a dose of $10 \mathrm{mg} / \mathrm{kg}$, MPEP reduced responding on the inactive lever. Attenuation of inactive lever responses could be interpreted as nonspecific motor impairment by MPEP at the highest dose. However, it is also possible that active and inactive lever responses are not completely independent of each other. For example, we have commonly seen that the number of both active and inactive lever responses decrease during extinction in our behavioral model. Therefore, suppression of responding at the inactive lever by MPEP could also be interpreted as response generalization. This conclusion is further supported by our locomotor activity measurements. Although MPEP reduced ethanol-induced locomotor stimulation, animals were not impaired under these conditions when compared to saline-treated control animals. In other studies MPEP at doses of $2.5-10 \mathrm{mg} / \mathrm{kg}$, delivered i.p., had also no effect on exploratory locomotor activity in rats (Tatarczynska et al, 2001; Henry et al, 2002; Paterson et al, 2003). However, another study indicated that much higher doses of MPEP and ethanol resulted in an additive effect of MPEP on ethanol-induced sedation in mice (Sharko and Hodge, 2003).

The reinstatement model appears to be useful for the study of the impact of conditioned cues on relapse to alcohol drinking; however, the usefulness of the reinstatement model in representing human relapse behavior has two important limitations (Spanagel, 2000). First, researchers to date have not conclusively demonstrated that rats going through a reinstatement procedure are truly ethanol dependent in the sense that they exhibit uncontrolled ethanol responding. Second, it appears that extinction of ethanol-seeking behavior usually plays only a minor role in alcoholic patients trying to achieve and maintain abstinence. Consequently, the reinstatement model may not accurately reflect the situation of abstinent alcoholics experiencing craving and relapse. Other aspects of relapse-like drinking behavior might be better covered by the $\mathrm{ADE}$, which is represented in rats in which long-term ethanol self-administration alternates with repeated ethanol deprivation phases.

In our ADE model, subchronic MPEP treatment also significantly reduced relapse-like drinking behavior in a dose-dependent manner without any observable side effects on body weight or total fluid intake. Although the ADE model has good predictive validity-pharmacological agents that have been shown to attenuate relapse rates in humans (acamprosate, naltrexone, and $5-\mathrm{HT}_{3}$-antagonists) also attenuate the ADE (Spanagel and Hölter, 2000; RoddHenricks et al, 2000) - this model has certain limitations to mimic the human situation. Thus the drinking profile of an $\mathrm{ADE}$ does not closely reflect the profile of relapse drinking in alcoholics (Spanagel, 2000) and furthermore little is known about the neuronal circuits involved in the ADE. However, it has been repeatedly shown that noncompetitive NMDA receptor antagonists abolish the ADE (Hölter et al, 1996, 2000; Bienkowski et al, 2001), suggesting a crucial role of NMDA receptors in mediating the ADE. The fact that synaptic transmission at NMDA receptors is modulated by simultaneous activation of mGluR5 (Sorensen and Conn, 2003) could at least provide a clue for the effects of MPEP on the ADE. This functional coupling could result from the postsynaptic association of NMDA receptors with a complex of proteins, which includes different scaffolding proteins (eg PSD-95, Homer, Shank), but other receptors including mGluR5 are also linked to this complex (Kotecha et al, 2003), and activation of mGluR5 can lead to an enhancement of NMDA receptor function through phosphorylation by protein kinase C (Hermans and Challiss, 2001; Schoepp and Conn, 1993). The high affinity of MPEP for mGluR5 receptors, which is more than 1000 -fold higher compared to NMDARs, makes it very unlikely that under the used conditions MPEP affects NMDARs directly (Oleary et al, 2000; Gubellini et al, 2001; Spooren et al, 2001; Kozela et al, 2003). In summary, the functional coupling of mGluR5 and NMDA receptor suggests that the blockade of mGluR5 by MPEP reduces glutamatergic signaling through NMDA receptors and thereby interacts with ethanol-seeking and relapse behavior.

Having the limitations of the animal models used in the present study in mind, it is proposed that pharmacological targeting of mGluR5 might be a promising therapeutic line to pursue in alcoholic patients. This assumption is supported by three other recent findings: (i) In a preliminary report it has been shown that MPEP decreases operant ethanol self-administration during periods of peak consumption in mice (Sharko et al, 2002). (ii) The finding that MPEP evokes anxiolytic- and antidepressant-like effects in rats (Tatarczynska et al, 2001; Pilc et al, 2002) also has implications for the treatment of alcoholism due to the high comorbidity with these psychiatric disorders. (iii) Furthermore, Harris et al (2002) showed that acamprosate exhibits binding and functional characteristics that are consistent with an mGluR5 antagonist. These authors further speculate that acamprosate's ability to reduce relapse rates in alcoholic patients may result from its alterations in glutamatergic neurotransmission through mGluR5s.

\section{ACKNOWLEDGEMENTS}

This study was supported by two BMBF Grants FKZ 01GS0117-identification and functional analysis of target genes involved in alcohol addiction (RS)/FKZ EB 01011300 - individually adapted therapy of alcoholism (RS), by a grant from the Finnish Foundation for Alcohol Research (PB), and an EC Grant QLG3-CT-2002-01048identification and validation of molecular targets for pharmacological treatment of alcohol dependence (TARGALC group) (RS, PH). We would like to thank Christiane Zacher for her assistance.

\section{REFERENCES}

Bienkowski P, Koros E, Kostowski W, Bogucka-Bonikowska A (2000). Reinstatement of ethanol seeking in rats: behavioral analysis. Pharmacol Biochem Behav 66: 123-128.

Bienkowski P, Krzascik P, Koros E, Kostowski W, Scinska A, Danysz W (2001). Effects of a novel uncompetitive NMDA receptor antagonist, MRZ 2/579 on ethanol self-administration and ethanol withdrawal seizures in the rat. Eur J Pharmacol 413: 81-89.

Chiamulera C, Epping-Jordan MP, Zocchi A, Marcon C, Cottiny C, Tacconi $S$ et al (2001). Reinforcing and locomotor stimulant 
effects of cocaine are absent in mGluR5 null mutant mice. Nat Neurosci 4: 873-874.

Chiamulera C, Valerio E, Tessari M (1995). Resumption of ethanolseeking behaviour in rats. Behav Pharmacol 6: 32-39.

Ciccocioppo R, Angeletti S, Weiss F (2001). Long-lasting resistance to extinction of response reinstatement induced by ethanolrelated stimuli: role of genetic ethanol preference. Alcohol Clin Exp Res 25: 1414-1419.

Gasparini F, Lingenhohl K, Stoehr N, Flor PJ, Heinrich M, Vranesic I et al (1999). 2-Methyl-6-(phenylethynyl)-pyridine (MPEP), a potent, selective and systemically active mGlu5 receptor antagonist. Neuropharmacology 38: 1493-1503.

Gubellini P, Saulle E, Centonze D, Bonsi P, Pisani A, Bernardi G et al (2001). Selective involvement of mGluR1 receptors I corticostriatal LTD. Neuropharmacology 40: 839-846.

Harris BR, Prendergast MA, Gibson DA, Rogers DT, Blanchard JA, Holley RC et al (2002). Acamprosate inhibits the binding and neurotoxic effects of trans-ACPD, suggesting a novel site of action at metabotropic glutamate receptors. Alcohol Clin Exp Res 26: $1779-1793$.

Henry SA, Lehmann-Masten V, Gasparini F, Geyer MA, Markou A (2002). The mGluR5 antagonist, but not the mGluR2/3 agonist LY314582, augments PCP effects in prepulse inhibition and locomotor activity. Neuropharmacology 43: 1199-1209.

Hermans E, Challiss RA (2001). Structural, signalling and regulatory properties of the group I metabotropic glutamate receptors: prototypic family C G-protein-coupled receptors. Biochem J 359: 465-484.

Hölter SM, Danysz W, Spanagel R (1996). Evidence for anticraving properties of memantine. Eur J Pharmacol 314: $\mathrm{R} 1-\mathrm{R} 2$.

Hölter SM, Danysz W, Spanagel R (2000). Novel uncompetitive $N$-methyl-D-Aspartate (NMDA)-receptor antagonist MRZ 2/579 suppresses ethanol intake in long-term ethanol-experienced rats and generalizes to ethanol cue in drug discrimination procedure. J Pharmacol Exp Ther 292: 545-552.

Hölter SM, Engelmann M, Kirschke C, Liebsch G, Landgraf R, Spanagel R (1998). Long-term ethanol self-administration with repeated ethanol deprivation episodes changes ethanol drinking pattern and increases anxiety-related behaviour during ethanol deprivation in rats. Behav Pharmacol 9: 41-48.

Katner SN, Magalong JG, Weiss F (1999). Reinstatement of alcoholseeking behavior by drug-associated discriminative stimuli after prolonged extinction in the rat. Neuropsychopharmacology 20: 471-479.

Kotecha SA, Jackson MF, Al-Mahrouki AA, Roder JC, Orser BA, MacDonald JF (2003). Co-stimulation of mGluR5 and NMDA receptors is required for potentiation of excitatory synaptic transmission in hippocampal neurons. $J$ Biol Chem 278: 27742-27749.

Kozela E, Pilc A, Popik P (2003). Inhibitory effects of MPEP, an mGluR5 antagonist, and memantine, an $N$-methyl-D-aspartate receptor antagonist, on morphine antinociceptive tolerance in mice. Psychopharmacology 165: 245-251.

Lê AD, Poulos CX, Harding S, Watchus J, Juzytsch W, Shaham Y (1999). Effects of naltrexone and fluoxetine on alcohol selfadministration and reinstatement of alcohol seeking induced by priming injections of alcohol and exposure to stress. Neuropsychopharmacology 21: 435-444.

Lê AD, Quan B, Juzytch W, Fletcher PJ, Joharchi N, Shaham Y (1998). Reinstatement of alcohol-seeking by priming injections of alcohol and exposure to stress in rats. Psychopharmacology 135: $169-174$.

Lê AD, Shaham Y (2002). Neurobiology of relapse to alcohol in rats. Pharmacol Ther 94: 137-156.

Liu X, Weiss F (2002). Additive effect of stress and drug cues on reinstatement of ethanol seeking: exacerbation by history of dependence and role of concurrent activation of corticotropin- releasing factor and opioid mechanisms. J Neurosci 22: 78567861.

Lu XY, Ghasemzadeh MB, Kalivas PW (1999). Expression of glutamate receptor subunit/subtype messenger RNAS for NMDAR1, GluR1, GluR2 and mGluR5 by accumbal projection neurons. Mol Brain Res 63: 287-296.

McGeehan AJ, Olive MF (2003). The mGluR5 antagonist MPEP reduces the conditioned rewarding effects of cocaine but not other drugs of abuse. Synapse 47: 240-242.

Oleary DM, Movsesyan V, Vicini S, Faden AI (2000). Selective mGluR5 antagonists MPEP and SIB-1893 decrease NMDA or glutamate-mediated neuronal toxicity through actions that reflect NMDA receptor antagonism. $\mathrm{Br} J$ Pharmacol 131: 1429-1437.

Paterson NE, Semenova S, Gasparini F, Markou A (2003). The mGluR5 antagonist MPEP decreased nicotine self-administration in rats and mice. Psychopharmacology 167: 257-264.

Pilc A, Klodzinska A, Branski P, Nowak G, Palucha A, Szewczyk B et al (2002). Multiple MPEP administrations evoke anxiolyticand antidepressant-like effects in rats. Neuropharmacology 43: 181-187.

Popik P, Wrobel M (2002). Morphine conditioned reward is inhibited by MPEP, the mGluR5 antagonist. Neuropharmacology 43: $1210-1217$.

Rodd-Henricks ZA, McKinzie DL, Edmundson VE, Dagon CL, Murphy JM, McBride WJ et al (2000). Effects of 5-HT(3) receptor antagonists on daily alcohol intake under acquisition, maintenance, and relapse conditions in alcohol-preferring $(\mathrm{P})$ rats. Alcohol 21: 73-85.

Romano C, Sesma MA, McDonald CT, O’Malley K, Van den Pool AN, Olney JW (1995). Distribution of metabotropic glutamate receptor mGluR5 immunoreactivity in rat brain. J Comp Neurol 355: 455-469.

Schachtman TR, Bills C, Ghinescu R, Murch K, Serfozo P, Simonyi A (2003). MPEP, a selective metabotropic glutamate receptor 5 antagonist, attenuates conditioned taste aversion in rats. Behav Brain Res 141: 177-182.

Schoepp DD, Conn PJ (1993). Metabotropic glutamate receptors in brain function and pathology. Trends Pharmacol Sci 14: 13-20.

Schulz B, Fendt M, Gasparini F, Lingenhohl K, Kuhn R, Koch M (2001). The metabotropic glutamate receptor antagonist 2methyl-6-(phenylethynyl)-pyridine (MPEP) blocks fear conditioning in rats. Neuropharmacology 41: 1-7.

Shaham Y, Shalev U, Lu L, de Wit H, Stewart J (2003). The reinstatement model of drug relapse: history, methodology and major findings. Psychopharmacology 168: 3-20.

Sharko AC, Hodge CW (2003). Involvement of metabotropic glutamate receptors subtype 5 (mGlu5) in ethanol-induced sedation. Alcohol Clin Exp Res S 27: 97A.

Sharko AC, Kimberly I, Koenig H, Lau K, Ou CJ, Olive MF et al (2002). Involvement of metabotropic glutamate receptor subtype 5 (mGluR5) in alcohol self-administration. Alcohol Clin Exp Res $S$ 26: $112 \mathrm{~A}$.

Shigemoto R, Nomura S, Ohishi H, Sugihara H, Nakanishi S, Mizuno N (1993). Immunohistochemical localization of a metabotropic glutamate receptor, mGluR5, in the rat brain. Neurosci Lett 163: 53-57.

Sinclair JD (1971). The alcohol-deprivation effect in monkeys. Psychonom Sci 25: 21-24.

Sorensen SD, Conn PJ (2003). G protein-coupled receptor kinases regulate metabotropic glutamate receptor 5 function and expression. Neuropharmacology 44: 699-706.

Spanagel R (2000). Recent animal models of alcoholism. Alcohol Res Health 24: 124-131.

Spanagel R, Bienkowski P (2002). Glutamatergic mechanisms in alcohol dependence and addiction. In: Lodge D, Danysz W, Parsons CG (eds). Therapeutic Potential of Ionotropic Glutamate 
Receptor Antagonists and Modulators. Graham Publishing Co.: Johnson city, TN, USA. pp 375-403.

Spanagel R, Hölter SM (1999). Long-term alcohol self-administration with repeated alcohol deprivation phases: an animal model of alcoholism? Alcohol Alcohol 34: 231-243.

Spanagel R, Hölter SM (2000). Pharmacological validation of a new animal model of alcoholism. J Neural Transm 107: 669-680.

Spanagel R, Zieglgänsberger W (1997). Anti-craving compounds for ethanol: new pharmacological tools to study addictive processes. Trends Pharmacol Sci 18: 54-59.

Spooren WP, Gasparini F, Salt TE, Kuhn R (2001). Novel allosteric antagonists shed light on mGlu(5) receptors and CNS disorders. Trends Pharmacol Sci 22: 331-337.

Tatarczynska E, Klodzinska A, Chojnacka-Wojcik E, Palucha A, Gasparini F, Kuhn R et al (2001). Potential anxiolytic- and antidepressant-like effects of MPEP, a potent, selective and systemically active mGlu5 receptor antagonist. $\mathrm{Br}$ J Pharmacol 132: 1423-1430.

Tsai G, Coyle JT (1998). The role of glutamatergic neurotransmission in the pathophysiology of alcoholism. Annu Rev Med 49: 173-184.

Vosler PS, Bombace JC, Kosten TA (2001). A discriminative twolever test of dizocilpine's ability to reinstate ethanol-seeking behavior. Life Sci 69: 591-598.

Wang JQ, Mao L, Parelkar NK, Tang Q, Liu Z, Sarwar S et al (2003). Glutamate-regulated behavior, transmitter release, gene expression and addictive plasticity in the striatum: roles of metabotropic glutamate receptors. Curr Neuropharmacol 1: $1-29$.

Weiss F, Porrino LJ (2002). Behavioral neurobiology of alcohol addiction: recent advances and challenges. J Neurosci 22: 3332-3337. 